\title{
Short communication: Short-term effect of 3-nitrooxypropanol on feed dry matter intake in lactating dairy cows
}

\author{
A. Melgar, ${ }^{1}$ K. Nedelkov, ${ }^{1,2}$ C. M. M. R. Martins, ${ }^{1,3}$ K. C. Welter, ${ }^{1,4}$ X. Chen, ${ }^{1,5}$ S. E. Räisänen, ${ }^{1}$ M. T. Harper, ${ }^{1}$ \\ J. Oh, ${ }^{1,6}$ S. Duval, ${ }^{7}$ and A. N. Hristov ${ }^{1 *}$ \\ ${ }^{1}$ Department of Animal Science, The Pennsylvania State University, University Park 16802 \\ ${ }^{2}$ Department of Animal Husbandry, Faculty of Veterinary Medicine, Trakia University, Stara Zagora 6000, Bulgaria \\ ${ }^{3}$ Department of Animal Nutrition and Production, School of Veterinary Medicine and Animal Science, University of São Paulo, \\ Pirassununga 13635-900, São Paulo, Brazil \\ ${ }^{4}$ Department of Animal Science, School of Food Engineering and Animal Science, University of São Paulo, Pirassununga 13635-900, São Paulo, \\ Brazil \\ ${ }^{5}$ School of Computing, University of Ulster, Co. Antrim, Northern Ireland, BT37 0QB, United Kingdom \\ ${ }^{6}$ Cargill Animal Nutrition, Seongnam, South Korea 13630 \\ ${ }^{7}$ Research Centre for Animal Nutrition and Health, DSM Nutritional Products, Saint Louis Cedex 68305, France
}

\begin{abstract}
The objective of this study was to investigate the effect of 3-nitrooxypropanol (3-NOP), an enteric methane inhibitor under investigation, on short-term dry matter intake (DMI) in lactating dairy cows. Following a 1-wk adaptation period, 12 multiparous Holstein cows were fed a basal total mixed ration (TMR) containing increasing levels of 3-NOP during 5 consecutive, 6 - $\mathrm{d}$ periods. The experiment was conducted in a tiestall barn. Feed bins were split in half by a solid divider, and cows simultaneously received the basal TMR supplemented with the following: (1) a placebo without 3 -NOP or (2) 3 -NOP included in the TMR at 30,60, 90, or $120 \mathrm{mg} /$ $\mathrm{kg}$ of feed dry matter (experimental periods 2, 3, 4, and 5 , respectively). Cows received the control diet (basal TMR plus placebo premix) during experimental period 1. A premix containing ground corn grain, soybean oil, and dry molasses was used to incorporate $3-\mathrm{NOP}$ in the ration. Cows were fed twice daily as follows: $60 \%$ of the daily feed allowance at $0800 \mathrm{~h}$ and $40 \%$ at $1800 \mathrm{~h}$. Feed offered and refused was recorded at each feeding. During the morning feedings, each cow was offered either control or 3 -NOP-treated TMR at $150 \%$ of her average intake during the previous $3 \mathrm{~d}$. After collection of the evening refusals, cows received only the basal TMR without the premix until the next morning feeding. The test period for the short-term DMI data collection was defined from morning feeding to afternoon refusals collection during each day of each experimental period. Location (left or right) of the control and 3-NOP diets
\end{abstract}

Received February 7, 2020.

Accepted July 29, 2020.

*Corresponding author: anh13@psu.edu within a feed bin was switched every day during each period to avoid feed location bias. Dry matter intake of TMR during the test period was quadratically increased by 3 -NOP compared with the control. Inclusion of $3-\mathrm{NOP}$ at $120 \mathrm{mg} / \mathrm{kg}$ of feed dry matter resulted in decreased 10-h DMI compared with the lower 3-NOP doses, but was similar to the control. There was no effect of feed location (left or right) within feed bin on DMI. Data from this short-term study suggests that 3 -NOP does not have a negative effect on DMI in lactating dairy cows.

Key words: 3-nitrooxypropanol, short-term dry matter intake, dairy cattle

\section{Short Communication}

The enteric methane inhibitor under investigation, 3-nitrooxypropanol (3-NOP), was developed by Duval and Kindermann (2012). Data from studies with beef cattle indicate decreased DMI when 3-NOP is included at 53,161 , and $345 \mathrm{mg} / \mathrm{kg}$ of feed DM (Romero-Pérez et al., 2014) and at 100 and $200 \mathrm{mg} / \mathrm{kg}$ of feed DM (Vyas et al., 2016). In beef animals that had not been previously exposed to 3-NOP, Lee et al. (2019) observed less preference for a diet with 3-NOP compared with a diet without 3 -NOP when offered a choice. These authors also observed that within $7 \mathrm{~d}$, the animals were accustomed to the 3 -NOP diet. Overall, long-term studies with 3-NOP have shown no negative effects of the inhibitor on DMI and lactation performance in dairy cows (Hristov et al., 2015; Melgar et al., 2019b; Van Wesemael et al., 2019). Melgar et al. (2020a), however, observed an approximately $5 \%$ decrease in DMI of early-lactation cows receiving $60 \mathrm{mg}$ of 3-NOP/ $\mathrm{kg}$ of feed DM (although there was no effect on DMI when expressed on a BW basis). The decreased DMI in 
that study did not affect milk or ECM yields, but the 3-NOP cows appeared to gain less BW than the control cows. Although this may not be a significant concern in practical dairy farming, as cows will recover body condition in late lactation and the dry period, it is important to understand if 3-NOP does affect DMI or if the data by Melgar et al. (2020a) were an artifact of the experimental design in that study. Feed intake in dairy cows can be affected by multiple factors (Allen, 1996, 2000), with palatability being one of them (Baumont, 1996). Anecdotal observations by researchers and barn staff involved in experiments with 3-NOP conducted at the Pennsylvania State University suggested that TMR containing 3-NOP may have had a distinct odor, which could potentially affect DMI (Goatcher and Church, 1970; Albright, 1993). According to Goatcher and Church (1970), cows use their senses to discriminate between feeds. Along with taste and chemosensory irritation, odor is one important chemical factor that can determine palatability and affect appetite (Baumont, 1996). With dairy cows, odoriferous compounds increased grass silage intake by about $8 \%$ over an 8 -wk period (Weller and Phipps, 1989). However, Dohi et al. (1991) reported that odor from cattle feces deterred cows from consuming the feed. Moreover, Spence (2015) suggested that the sense of smell (or olfaction) contributes most of the information to the chemical fragment of the feed-palatability complex. Therefore, the objective of the current experiment was to investigate if organoleptic characteristics (smell and odor or taste) of a TMR containing 3-NOP would have any adverse effect on short-term DMI in lactating dairy cows. We hypothesized that, when offered simultaneously, short-term DMI would be similar between TMR with and without 3-NOP.

Animals involved in the experiment were cared for according to the guidelines of The Pennsylvania State University Institutional Animal Care and Use Committee. The committee reviewed and approved the experiment and all procedures involving animals. The study was conducted with 12 multiparous Holstein cows, averaging $( \pm \mathrm{SD}) 74 \pm 22 \mathrm{DIM}, 53 \pm 12 \mathrm{~kg}$ of milk yield, and $630 \pm 146 \mathrm{~kg}$ of $\mathrm{BW}$, at The Pennsylvania State University's Dairy Teaching and Research Center's tiestall barn (University Park, PA). Feed bins were split in half by a solid divider and, following a 1-wk adaptation to the barn environment, cows received a control diet (without 3-NOP) on both sides of the feed bin for $6 \mathrm{~d}$ (period 1). Starting with period 2, all 12 cows simultaneously received 2 diets, 1 without 3 -NOP (control) and 1 with 3 -NOP included at 30 (period 2), 60 (period 3), 90 (period 4), or 120 (period 5) mg/ $\mathrm{kg}$ of feed on a DM basis (treatments were 30NOP,
60NOP, 90NOP, and 120NOP, respectively). Each treatment was offered sequentially to all cows for $6 \mathrm{~d}$; therefore, the experiment consisted of five 6- $\mathrm{d}$ experimental periods. The 3-NOP inclusion rates were based on previous long-term experiments conducted in our laboratory (40-80 mg of 3-NOP/ $\mathrm{kg}$ of feed DM; Hristov et al., 2015; Melgar et al., 2020a), and higher rates of 3 -NOP (90 and $120 \mathrm{mg} / \mathrm{kg}$ of DM) were included to exaggerate the effect of treatment on the organoleptic characteristics of the TMR as related to short-term DMI. Location (left or right) of the control and 3-NOP TMR within a feed bin were identified with a color band (i.e., yellow for control and blue for 3-NOP TMR) and sides were switched daily before the morning feeding to avoid feed location bias; therefore, each treatment TMR was located at each side of the feed bin for a total of $3 \mathrm{~d}$ during each experimental period.

The basal TMR contained the following (\%, DM basis): corn silage, 39; alfalfa haylage, 11; grass hay, 4; corn grain ground, 12; corn grain cracked, 2; soybean seed roasted, 8; canola meal, 7; candy byproduct meal, 7; whole cottonseed, 3 ; molasses, 5; and a mineralvitamin premix, 2. Chemical composition of the diet was as follows (\%, DM basis or as indicated): CP, 16.5; $\mathrm{NDF}, 29.4 ; \mathrm{ADF}, 19.1 ; \mathrm{NE}_{\mathrm{L}}, 1.76 \mathrm{Mcal} / \mathrm{kg} ; \mathrm{NFC}, 48$; ash, 6.7; Ca, 0.82; and P, 0.44. Supplementation of 3 -NOP to the basal TMR was through a premix containing the following (\%,DM basis): ground corn grain, 60; soybean oil, 5; dry molasses, 15; and an active or placebo supplement, 20 (both from DSM Nutritional Products, Basel, Switzerland). The active supplement contained $10.9 \% 3-\mathrm{NOP}$ on $\mathrm{SiO}_{2}$ and propylene glycol, and the placebo supplement contained $\mathrm{SiO}_{2}$ and propylene glycol only. Both control and 3-NOP premixes were prepared and properly labeled the day before the start of each experimental period, kept at $4^{\circ} \mathrm{C}$ in sealed containers with no headspace, and mixed with the basal TMR every morning replacing an equivalent amount of TMR. The inclusion rate of the premix was adjusted according to the targeted 3-NOP concentration for each experimental period and DM of the basal TMR. Cows were fed ad libitum twice daily (at approximately 0800 and $1800 \mathrm{~h}$ ) and had free access to drinking water. The basal TMR was prepared using a stationary mixer (Electra-Mix, model 1062, I. H. Rissler; Mohnton, PA), and separate mixers (Rissler Mobile TMR Mixer Model 1050; I. H. Rissler) were used to mix the control and 3 -NOP TMR. The daily DM allowance was split as $60 \%$ fed at the morning feeding and $40 \%$ fed at the evening feeding. Feed offered and refused was recorded at each feeding. During the morning feedings, each cow was offered either control or 3-NOP TMR at $150 \%$ of her normal intake during the previous $3 \mathrm{~d}$. One-third of 
each TMR (i.e., control and 3-NOP) allocated for the morning feeding was stored in 20-kg plastic containers and fed around $1300 \mathrm{~h}$ due to limited space in the feed bins. The plastic containers were color-coded to match the color on the feed bin side assigned to the each TMR for that day. The basal TMR without the premix was stored in 1 Rissler mixer until fed after collection of the afternoon feeding refusals. Cows received only the basal TMR (i.e., without the 3 -NOP or placebo premixes) until the next morning feeding, and feed was pushed up to the cows 4 to 6 times daily. The intention of this interrupted offering of 3-NOP TMR was to avoid adaptation, and thus to be able to evaluate the effect of short-term exposure to 3-NOP-supplemented feed on DMI.

The amount of feed offered and refused was weighed individually and recorded for each cow from each location side (left or right of the feed bin) at the morning and evening feedings to measure daily as-fed intake during the entire experiment. The test period for shortterm DMI data was defined from 0800 to $1800 \mathrm{~h}$ (i.e., from morning feeding to afternoon refusals collection) during each day of each experimental period. Samples of the TMR and refusals were collected every $3 \mathrm{~d}$ and stored at $-20^{\circ} \mathrm{C}$. Dry matter content of the TMR and refusals was determined by drying at $55^{\circ} \mathrm{C}$ for $72 \mathrm{~h}$ in a forced-air oven and used to calculate DMI from the asfed TMR intake data. Samples of the feed ingredients were collected throughout the experiment, composited, dried for the TMR samples, and ground in a Wiley Mill (Thomas Scientific; Swedesboro, NJ) through a 1-mm sieve. Samples were submitted to Cumberland Valley Analytical Services (Waynesboro, PA) for chemical composition analyses. Analyzed chemical composition of the individual feed ingredients and their inclusion rate in the TMR were used to calculated chemical composition of the basal TMR.

Cows were milked twice daily at 0600 and $1800 \mathrm{~h}$, and milk production was recorded at each milking. Milk samples were collected during d 4 (p.m. milking) and d 5 (a.m. milking) of the adaptation and experimental periods. An aliquot of each milk sample was placed in tubes with a preservative (2-bromo-2-nitropropane-1, 3-diol) and submitted to Dairy One Cooperative, Inc. (Ithaca, NY) for analysis of milk fat, true protein, and lactose using Milkoscan models 6000, FT+ (Foss Electric A/S, Hillerød, Denmark). Milk from 3-NOP-fed cows was discarded for the duration of the study and for an additional 7-d after the study was completed.

All data were analyzed using SAS, version 9.4 (SAS Institute Inc., Cary, NC). Data were tested for normality using the UNIVARIATE procedure. Short-term (10-h) DMI data were analyzed using the MIXED pro- cedure. A total of 576 observations were used in the 10-h DMI analysis $[12$ cows $\times 4$ periods (period 1 data were not included in the analysis) $\times 6 \mathrm{~d} \times 2$ sides of the feed bin]. The model included treatment (control and 3 -NOP), side (left and right side of the feed bin), and treatment $\times$ side interaction. Overall, 24-h DMI was analyzed with treatment, day of TMR offering, and the interaction treatment $\times$ day of TMR offering. A total of 360 observations were used in the 24-h DMI analysis [12 cows $\times 5$ periods (period 1 data were included in the analysis $) \times 6 \mathrm{~d}$. In both models, cow was a random effect and all others were fixed. Data were also analyzed using orthogonal and polynomial contrasts to evaluate 3-NOP treatments versus control and linear and quadratic effects of 3-NOP inclusion rate. Data are presented as least squares means. Statistical differences were considered significant at $P \leq 0.05$ and a trend toward significance at $0.05<P \leq 0.10$. Descriptive statistics for the production data (milk yield and milk composition) were computed using the MEANS procedure.

Due to the nature of the experimental design of the study (short-term and partial treatment of the TMR offered to the cows), milk yield and milk composition data are not reported in tables and are presented here only as a reference. Average milk yield was 50.9, 51.0, $48.6,49.6$, and $49.9 \mathrm{~kg} / \mathrm{d}(\mathrm{SEM}=2.91 \mathrm{~kg} / \mathrm{d})$ for control, 30NOP, 60NOP, 90NOP, and 120NOP, respectively. During the experiment, milk fat, milk true protein, and lactose averaged $( \pm \mathrm{SEM}) 3.55 \pm 0.154 \%, 2.78 \pm$ $0.035 \%$, and $4.86 \pm 0.033 \%$, respectively.

Samples of TMR were analyzed for 3-NOP concentration by DSM Nutritional Products (Global R and D Analytics, Kaiseraugst, Switzerland). Analyzed concentrations of $3-\mathrm{NOP}$ in the TMR were $0,30.6,60.0$, 92.8 , and $120.5 \mathrm{mg} / \mathrm{kg}$ of feed DM for control, 30NOP, $60 \mathrm{NOP}, 90 \mathrm{NOP}$, and 120NOP, respectively. Relative standard deviation was below $3.1 \%$ for each 3 -NOP level set of samples.

Table 1 contains both 10 -h test period and overall 24-h DMI data. During the 10-h test period, DMI was increased $(P<0.001$; quadratic effect) by 3 -NOP. Compared with control, 3 -NOP increased $(P<0.001)$ 10-h DMI by 26,27 , and $35 \%$ (30, 60, and $90 \mathrm{mg}$ of 3 -NOP/ $\mathrm{kg}$ of feed DM, respectively. The 10-h test period DMI for the highest dose of 3-NOP was not different $(P=$ 0.35; not shown in Table 1) from the control. Overall, 24-h DMI, which included 3-NOP and control TMR followed by basal TMR offerings, was not affected $(P$ $=0.33$ ) by 3 -NOP compared with the control. Rate of 3 -NOP inclusion had no effect $(P \geq 0.14)$ on 24 -h DMI of the cows. Both effect of day (of treatment) and treatment $\times$ day interaction were significant $(P<0.001$; 
Table 1, footnote 4) for 24-h DMI. Plotting the 24-h DMI data showed variability in the day-to-day DMI, but no visible trends over the course of treatment $(6 \mathrm{~d})$. The interaction treatment $x$ day appeared to be caused by differences in DMI among treatments during the first $3 \mathrm{~d}$ of the experimental periods, similar DMI on $\mathrm{d}$ 4 , and lower DMI for $30 \mathrm{NOP}$ on d 5 (data not shown). Kim et al. (2019) fed $100 \mathrm{mg}$ of $3-\mathrm{NOP} / \mathrm{kg}$ of feed DM with a high-forage or a high-grain diet and observed no effect of 3-NOP on DMI in beef cattle. These authors reported no effect of 3-NOP on feeding behavior or feed sorting in both experiments (i.e., high-forage or highgrain diets). Supplementation with $3-\mathrm{NOP}$ at $100 \mathrm{mg} /$ $\mathrm{kg}$ of feed DM in a short-term eating-preference study in beef cattle fed high-forage or high-grain diets showed no effect of 3-NOP supplementation on DMI (Lee et al., 2019). Similarly, a short-term dose-response study by Melgar et al. (2020b) with mid-lactation dairy cows suggested that inclusion of $3-\mathrm{NOP}$ in doses up to 200 $\mathrm{mg} / \mathrm{kg}$ of feed DM, administered via the TMR, had no effect on DMI when compared with the control; however a linear tendency for decreased DMI was observed with increasing 3-NOP dose. Vyas et al. (2018) also reported that increased inclusion rate of 3-NOP decreased DMI by 7 and $5 \%$ during the backgrounding and finishing phases in beef cattle, respectively. A recent 3 -NOP meta-analysis of beef and dairy data (Kim et al., 2020) also reported an overall decrease in DMI with 3-NOP.

As indicated earlier, the basis for the current study was as follows: (1) a clearly distinct odor of the 3-NOP TMR compared with the control TMR, sensed by project staff in several experiments conducted at our dairy facility, and (2) the lower absolute DMI by 3-NOP cows reported in Melgar et al. (2020a). Dry matter intake in dairy cows is affected by several important factors, including gut and rumen fill and chemostatic mechanisms (Allen, 2000). In the current preference study, however, we focused on the short-term effects of 3-NOP on DMI. Clearly, gut fill did not play a role in the current experiment because cows were fed the same basal diet and there was no data indicating that feed passage rate was directly affected by 3 -NOP. We also believe chemostatic regulation of DMI was unlikely due to the short-term nature of our experiment. In addition, we have not seen an increase in the absolute concentration of propionate in ruminal fluid of cows receiving 3 -NOP (Lopes et al., 2016; Melgar et al., 2020a), although molar proportion of propionate may increase (Lopes et al., 2016; Kim et al., 2019-beef steers fed a high-forage diet). We also point out that in the current experiment (1) cows always had access to and a choice between 3 -NOP and control TMR during the 10-h test period, and (2) 3-NOP and control TMR were offered for 10 $\mathrm{h}$ only, and then cows were offered the control TMR for the remaining $14 \mathrm{~h}$ of the feeding cycle. Thus, it appeared that the lack of effect of 3-NOP on short-term DMI in the current experiment was most likely a result of lack of effect of the compound on the organoleptic properties of the feed. Kim et al. (2019) arrived at a similar conclusion in beef cattle. Although cows in the current experiment had access to 3-NOP TMR for only $10 \mathrm{~h} / \mathrm{d}$, the possibility of carry-over effects of residual sensations from previous sensory experiences (Lawless and Heymann, 1998) on short-term DMI cannot be eliminated. Our assumption, however, is that these potential carry-over effects were minimized due to the

Table 1. Dry matter intake during the 10-h test period and overall 24-h period of a TMR containing increasing levels of 3-nitrooxypropanol $(3-\mathrm{NOP})$ in dairy cows

\begin{tabular}{|c|c|c|c|c|c|c|c|c|c|c|}
\hline \multirow[b]{2}{*}{ Item $^{1}$} & \multicolumn{5}{|c|}{ Treatment $^{2}$} & \multirow[b]{2}{*}{$\mathrm{SEM}^{3}$} & \multicolumn{4}{|c|}{$P$-value ${ }^{4}$} \\
\hline & Control & $30 \mathrm{NOP}$ & $60 \mathrm{NOP}$ & $90 \mathrm{NOP}$ & $120 \mathrm{NOP}$ & & Overall & $\begin{array}{l}\text { Control } \\
\text { vs. Trt }\end{array}$ & $\mathrm{L}$ & $\mathrm{Q}$ \\
\hline 24-h DMI & 26.7 & 26.9 & 25.6 & 27.4 & 25.7 & 0.94 & $<0.001$ & 0.33 & 0.14 & 0.62 \\
\hline
\end{tabular}

${ }^{1}$ Feed with or without 3-NOP was offered during a 10-h test period, after which only feed without 3-NOP or placebo supplements (i.e., basal TMR) was offered to the cows for the remaining $14 \mathrm{~h}$.

${ }^{2}$ Treatments were control (no 3-NOP) and 3-NOP included at (mg/kg of feed DM) 30, 60, 90, and 120 (30NOP, 60NOP, 90NOP, and 120NOP, respectively). Cows received the control diet on both sides of the feed bin in period 1; starting with period 2, cows simultaneously received 2 diets, 1 without 3-NOP (control) and 30NOP (period 2), 60NOP (period 3), 90NOP (period 4), or 120NOP (period 5). Measured concentration of 3-NOP in TMR were $0,30.6,60.0,92.8$, and $120.5 \mathrm{mg} / \mathrm{kg}$ of feed DM, for each dose level, respectively. Data are presented as LSM.

${ }^{3}$ Largest SEM are published in table; $\mathrm{n}=576$ for 10 -h DMI and $\mathrm{n}=360$ for 24 -h DMI (n represents number of observations used in the statistical analysis).

${ }^{4} P$-values for the overall treatment effect and contrasts; Control vs. Trt $=$ control vs. all 3-NOP treatments; L $=$ linear effect of 3-NOP dose; $\mathrm{Q}$ $=$ quadratic effect of 3-NOP dose. For 10-h DMI: effect of feed location side (left or right), $P=0.51$; treatment $\times$ feed location side interaction, $P=0.002$. For 24-h DMI: effect of day, $P<0.001$; treatment $\times$ day interaction, $P<0.001$. 
longer $(14 \mathrm{~h})$ exposure to untreated, control TMR. In sensory evaluation studies, techniques such as washout periods and using of palate cleansers have been proposed to minimize carry-over effects during tasting (Johnson and Vickers, 2004).

Digestible feed energy not converted into enteric methane, due to inhibition of methanogenesis as the case with 3-NOP, has the potential to increase energy availability for productive purposes. Milk production or BW gain responses to 3-NOP, however, have been inconsistent (Melgar et al., 2020a). More recently, we performed a meta-analysis of long-term 3-NOP studies conducted at The Pennsylvania State University and reported an overall moderate increase in milk fat concentration with 3-NOP compared with untreated control diets (Melgar et al., 2019b). If confirmed, this response can be a stimulus for dairy producers to adopt the use of 3-NOP in their operations once it becomes available.

Overall, there was no effect $(P=0.51)$ of feed location side on the 10-h test period DMI in the current study (Table 1, footnote 4). There was, however, a treatment $\times$ feed location side interaction $(P=0.002)$ for 10-h DMI. Analysis of this interaction (Figure 1) indicated that during the 30NOP treatment period, cows had higher $(P<0.001)$ 10-h DMI from the right side than the left side of the feed bin. After this initial 3-NOP inclusion period, no feed location side effect on DMI was observed, suggesting that the interaction may have been a result of an initial adjustment of the cows to the experimental setup.

Data from this short-term study suggest that 3-NOP does not have a negative effect on TMR DMI, which was our original concern based on anecdotal observations by research staff involved in 3 -NOP studies conducted at The Pennsylvania State University. In fact, we observed a quadratic increase in the 10-h TMR DMI with 3-NOP versus the control. Long-term studies have reported no effect or decreased DMI by lower doses of 3-NOP in dairy cattle (Hristov et al., 2015; Melgar et al., 2019a; Van Wesemael et al., 2019; 3-NOP included up to $80 \mathrm{mg} / \mathrm{kg}$ of $\mathrm{DM}$ ). The current data suggest that within the maximum effectiveness range of 3-NOP inclusion (up to $100 \mathrm{mg} / \mathrm{kg}$ of feed DM; Melgar

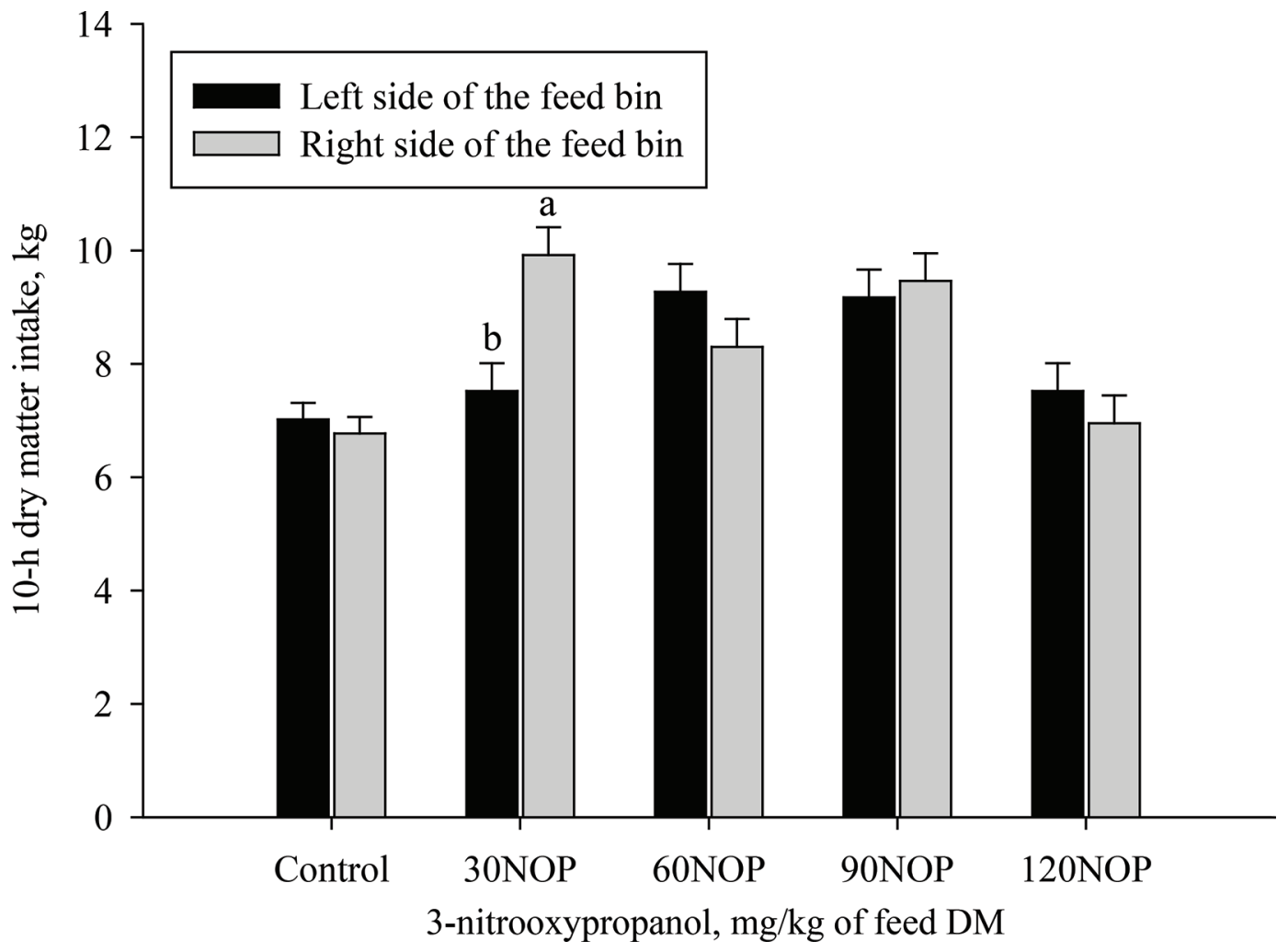

Figure 1. Treatment by feed location side (left or right location in the feed bin) interaction for DMI during a 10-h test period of a TMR containing 3-nitrooxypropanol (3-NOP) in dairy cows. Treatments were control or 3-NOP levels at $(\mathrm{mg} / \mathrm{kg}$ of feed of DM) 30, 60, 90, and 120 for $30 \mathrm{NOP}, 60 \mathrm{NOP}, 90 \mathrm{NOP}$, and $120 \mathrm{NOP}$, respectively. Data are presented as LSM and bars represent SEM; $\mathrm{n}=72$ (number of independent data points for each mean value). Overall, treatment $\times$ feed location side interaction, $P=0.002$. Means with different letters (a,b) within feed location side differ at $P<0.05$. 
et al., 2020b), organoleptic properties are not likely to affect short-term DMI of a diet containing 3-NOP in lactating dairy cows. We noted that our data pertain to the effect of 3-NOP only and not the supplement used to deliver 3-NOP (which also contains $\mathrm{SiO}_{2}$ and propylene glycol). Propylene glycol, for example, may not be palatable to dairy cows and may decrease DMI (Nielsen and Ingvartsen, 2004). There are some indications, however, that $\mathrm{SiO}_{2}$ may increase feed intake in some livestock species (Martel-Kennes et al., 2016; Ikusika et al., 2019).

\section{ACKNOWLEDGMENTS}

This work was supported by the USDA (Washington, DC) National Institute of Food and Agriculture Federal Appropriations under Project PEN 04539 and Accession number 1000803. The authors thank DSM Nutritional Products (Basel, Switzerland) for providing partial financial support for the project and for supplying 3-NOP. The authors also thank the staff of the Pennsylvania State University's Dairy Teaching and Research Center (University Park) for their conscientious care and management of the animals and for technical assistance during the study. A. Melgar was supported by the Government of Panama through the IFARHU-SENACYT Scholarship Program (Clayton, City of Knowledge, Panama) and the Agricultural Research Institute of Panama (IDIAP; Clayton, City of Knowledge, Panama). The authors have not stated any conflicts of interest.

\section{REFERENCES}

Albright, J. L. 1993. Feeding behavior of dairy cattle. J. Dairy Sci. 76:485-498. https://doi.org/10.3168/jds.S0022-0302(93)77369-5.

Allen, M. S. 1996. Physical constraints on voluntary intake of forages by ruminants. J. Anim. Sci. 74:3063-3075. https://doi.org/10 $.2527 / 1996.74123063 x$.

Allen, M. S. 2000. Effects of diet on short-term regulation of feed intake by lactating dairy cattle. J. Dairy Sci. 83:1598-1624. https:// doi.org/10.3168/jds.S0022-0302(00)75030-2.

Baumont, R. 1996. Palatability and feeding behaviour in ruminants. A review. Ann. Zootech. 45:385-400. https://doi.org/10.1051/ animres:19960501.

Dohi, H., A. Yamada, and S. Entsu. 1991. Cattle feeding deterrents emitted from cattle feces. J. Chem. Ecol. 17:1197-1203. https:// doi.org/10.1007/BF01402943.

Duval, S., and M. Kindermann. 2012. Use of nitrooxy organic molecules in feed for reducing methane emission in ruminants, and/ or to improve ruminant performance. World Intellectual Property Organization, assignee. Pat. No. WO 2012/084629 A1.

Goatcher, W. D., and D. C. Church. 1970. Taste responses in ruminants. 1. Reactions of sheep to sugars, saccharin, ethanol and salts. J. Anim. Sci. 30:777-783. https://doi.org/10.2527/jas1970 .305777x.

Hristov, A. N., J. Oh, F. Giallongo, T. W. Frederick, M. T. Harper, H. L. Weeks, A. F. Branco, P. J. Moate, M. H. Deighton, S. R. O. Williams, M. Kindermann, and S. Duval. 2015. An inhibitor persistently decreased enteric methane emission from dairy cows with no negative effect on milk production. Proc. Natl. Acad. Sci. USA 112:10663-10668. https://doi.org/10.1073/pnas.1504124112.

Ikusika, O. O., C. T. Mpendulo, T. J. Zindove, and A. I. Okoh. 2019. Fossil shell flour in livestock production: A review. Animals (Basel) 9:70. https://doi.org/10.3390/ani9030070.

Johnson, E. A., and Z. Vickers. 2004. The effectiveness of palate cleansing strategies for evaluating the bitterness of caffeine in cream cheese. Food Qual. Prefer. 15:311-316. https://doi.org/10 .1016/S0950-3293(03)00071-5.

Kim, H., H. G. Lee, Y. C. Baek, S. Lee, and J. Seo. 2020. The effects of dietary supplementation with 3-nitrooxypropanol on enteric methane emissions, rumen fermentation, and production performance in ruminants: a meta-analysis. J. Anim. Sci. Technol. 62:31-42. https://doi.org/10.5187/jast.2020.62.1.31

Kim, S-H., C. Lee, H. A. Pechtl, J. M. Hettick, M. R. Campler, M. D. Pairis-Garcia, K. A. Beauchemin, P. Celi, and S. M. Duval. 2019. Effects of 3-nitrooxypropanol on enteric methane production, rumen fermentation, and feeding behavior in beef cattle fed a highforage or high-grain diet. J. Anim. Sci. 97:2687-2699. https://doi .org/10.1093/jas/skz140.

Lawless, H. T., and H. Heymann. 1998. Sensory Evaluation of Food: Principles and Practices. Chapman and Hall Press, New York, NY.

Lee, C., S. H. Kim, K. Beauchemin, P. Celi, and S. Duval. 2019. Short-term eating preference of beef cattle fed high forage or high grain diets supplemented with 3-nitrooxypropanol. Animals (Basel) 10:64. https://doi.org/10.3390/ani10010064.

Lopes, J. C., L. F. de Matos, M. T. Harper, F. Giallongo, J. Oh, D. Gruen, S. Ono, M. Kindermann, S. Durval, and A. N. Hristov. 2016. Effect of 3-nitrooxypropanol on methane and hydrogen emissions, methane isotopic signature, and ruminal fermentation in dairy cows. J. Dairy Sci. 99:5335-5344. https://doi.org/10.3168/ jds.2015-10832.

Martel-Kennes, Y., J. Lévesque, and C. Decaux. 2016. Effect of crystalline silicon dioxide in piglet feed on growth performance with different levels of growth promoters. J. Anim. Sci. 94(Suppl. 5):488. https://doi.org/10.2527/jam2016-1020 (Abstr.).

Melgar, A., M. T. Harper, J. Oh, F. Giallongo, M. E. Young, T. L. Ott, S. Duval, and A. N. Hristov. 2020a. Effects of 3-nitrooxypropanol on rumen fermentation, lactational performance, and the resumption of ovarian cyclicity in dairy cows. J. Dairy Sci. 103:410-432. https://doi.org/10.3168/jds.2019-17085.

Melgar, A., C. F. A. Lage, K. Nedelkov, S. E. Räisänen, H. Stefenoni, M. E. Young, X. Chen, J. Oh, S. Duval, M. Kindermann, N. D. Walker, and A. N. Hristov. 2019a. Effects of 3-nitrooxypropanol on enteric methane emission and lactational performance of dairy cows. J. Dairy Sci. 102(E-Suppl. 1):428.

Melgar, A., N. D. Walker, and A. N. Hristov. 2019b. Enteric gas emissions and lactational performance of dairy cows fed 3-nitrooxypropanol: A meta-analysis. Page 51 in Proceedings of the 7 th International Greenhouse Gas and Animal Agriculture Conference, Iguassu Falls, Brazil. Embrapa Southeast Livestock, São Carlos, SP.

Melgar, A., K. C. Welter, K. Nedelkov, C. M. M. R. Martins, M. T. Harper, J. Oh, S. E. Räisänen, X. Chen, S. F. Cueva, S. Duval, and A. N. Hristov. 2020b. Dose-response effect of 3-nitrooxypropanol on enteric methane emission in dairy cows. J. Dairy Sci 103:6145-6156. https://doi.org/10.3168/jds.2019-17840.

Nielsen, N. I., and K. L. Ingvartsen. 2004. Propylene glycol for dairy cows: A review of the metabolism of propylene glycol and its effects on physiological parameters, feed intake, milk production and risk of ketosis. Anim. Feed Sci. Technol. 115:191-213. https://doi .org/10.1016/j.anifeedsci.2004.03.008.

Romero-Pérez, A., E. K. Okine, S. M. McGinn, L. L. Guan, M. Oba, S. M. Duval, M. Kindermann, and K. A. Beauchemin. 2014. The potential of 3-nitrooxypropanol to lower enteric methane emissions from beef cattle. J. Anim. Sci. 92:4682-4693. https://doi.org/10 $.2527 /$ jas.2014-7573.

Spence, C. 2015. Multisensory flavor perception. Cell 161:24-35. https: //doi.org/10.1016/j.cell.2015.03.007.

Van Wesemael, D., L. Vandaele, B. Ampe, H. Cattrysse, S. Duval, M. Kindermann, V. Fievez, S. De Campeneere, and N. Peiren. 2019 
Reducing enteric methane emissions from dairy cattle: Two ways to supplement 3-nitrooxypropanol. J. Dairy Sci. 102:1780-1787. https://doi.org/10.3168/jds.2018-14534.

Vyas, D., A. W. Alemu, S. M. McGinn, S. M. Duval, M. Kindermann, and K. A. Beauchemin. 2018. The combined effects of supplementing monensin and 3-nitrooxypropanol on methane emissions, growth rate, and feed conversion efficiency in beef cattle fed high forage and high grain diets. J. Anim. Sci. 96:2923-2938. https:// doi.org/10.1093/jas/sky174.
Vyas, D., S. M. McGinn, S. M. Duval, M. Kindermann, and K. A. Beauchemin. 2016. Effects of sustained reduction of enteric methane emissions with dietary supplementation of 3-nitrooxypropanol on growth performance of growing and finishing beef cattle. J. Anim. Sci. 94:2024-2034. https://doi.org/10.2527/jas.2015-0268.

Weller, R., and R. Phipps. 1989. Preliminary studies on the effect of flavouring agents on the dry-matter intake of silage by lactating dairy cows. J. Agric. Sci. 112:67-71. https://doi.org/10.1017/ S0021859600084112. 